\title{
FIBROMIALGIA: O QUE É, CAUSAS, SINTOMAS, DOENÇAS RELACIONADAS, TRATAMENTOS E ATUAÇÃO PSICOLÓGICA
}

\author{
OLIVEIRA, Maria Rosa ${ }^{1}$ \\ ROCHA, Sinara da ${ }^{2}$
}

RESUMO: O objetivo geral deste trabalho foi descrever sobre a síndrome de fibromialgia e a contribuição da psicologia neste contexto. Para tanto, é necessário evidenciar os objetivos específicos na identificação do perfil epidemiológicos da população acometida pela síndrome; discutir as causalidades da patologia e apontar as principais teorias e técnicas psicológicas sobre a síndrome Fibromialgica. Realizou-se, então, uma pesquisa metodológica cientifica adotando para o desenvolvimento deste trabalho a pesquisa bibliográfica nas bases de dados BVS-PSI, SCIELO, buscando artigos científicos no período de 2013 a 2019, sendo, resumos publicados em teses, dissertações, trabalho de conclusão de curso, livros e biblioteca virtual. Diante disso, verifica-se que para o desenvolvimento desta pesquisa, a maior dificuldade encontrada foi por ter poucos artigos relacionados com a temática deste trabalho; desta forma, este trabalho não esgota as pesquisas a respeito do tema, restando ainda abordagens e lacunas a serem estudadas, sugere-se novas pesquisas. O que impõe a constatação de que a problematização da pesquisa obteve como resposta a indagação: quais os aspectos da atuação do psicólogo que auxiliam no tratamento de pacientes fibromialgico? Em resposta, conclui-se que diversas técnicas e abordagens no decorrer da pesquisa mostraram se eficazes no tratamento de pacientes com essa patologia ou outras comorbidades, especialmente, a aplicação das técnicas psicoterapêuticas que demonstraram apresentar um maior alívio das dores. Ainda, recuperam sua autoestima, apresentam uma evolução nos quadros de ansiedade e depressão, bem como, na qualidade do sono. Especialmente, nas orientações aos familiares na sensibilização de conhecerem os aspectos da síndrome e, poderem compreender o seu portador e de quão importante é o seu apoio durante o tratamento e a manutenção.

Palavra-chave: Dor Crônica. Psicologia. Intervenção. Psicoterapia.

\section{FIBROMYALGIA: WHAT IT IS, CAUSES, SYMPTOMS, RELATED DISEASES, TREATMENTS AND PSYCHOLOGICAL ACTION}

\begin{abstract}
SUMMARY: The general objective of this study was to describe under the syndrome of fibromyalgia and the contribution of psychology in this context. Therefore, it is necessary to highlight the specific objectives in the identification of the epidemiological profile of the population affected by the syndrome; discuss the causalities of the pathology and point out the main theories and psychological techniques about Fibromyalgia syndrome. A scientific methodological research was carried out, adopting the revision of bibliographical research in the databases BVS-PSI, SCIELO, searching for scientific articles in the period from 2013 to 2019, being published in theses, dissertations, course completion work, books and virtual library. In view of this, it is verified that for the development of this research, the greatest difficulty was found to have few articles related to the topic since work, this way, this work does not exhaust the researches on the subject, still remaining approaches and gaps to be studied, new research is suggested. What imposes the finding that the questioning of the research obtained the answer to the question: what aspects of the psychologist's role in the treatment of fibromyalgic patients? In response, it is concluded that several techniques and approaches in the course of the research have shown to be effective in the treatment of patients with this pathology or other comorbidities, especially the application of psychotherapeutic techniques that have demonstrated greater relief of pain. Still, they recover their self-esteem, present an evolution in the pictures of anxiety and depression, as well as, in the quality of sleep. Especially, in the orientation of the family members in the awareness of knowing the aspects of the syndrome and of being able to understand the patient and how important their support is during treatment and maintenance.
\end{abstract}

Keywords: Chronic Pain. Psychology. Intervention. Psychotherapy.

\footnotetext{
${ }^{1}$ FAMA-Faculdade da Amazonia - Area da Saúde Psicologia

${ }^{2}$ Faculdade da Amazônia campus Vilhena/RO - Acadêmica do Curso de Psicologia da FAMA
} 


\section{INTRODUÇÃO}

\section{FIBROMIOALGIA}

A Fibromialgia (FM) é uma patologia incurável qualificada por dores musculares generalizada prolixa, cansaço e dificuldade no sono, o que acarreta prejuízo físico, psicológico aos seus usuários. No entanto, existe uma etiologia pouco conhecida e que comumente ataca mulheres com faixa etária entre 35 a 60 anos de idade (TORQUATO, 2019).

Este trabalho descreve um tema atual e de suma importância, sendo, a fibromialgia (FM), que se desenvolve possivelmente por condições emocionais e psicossomáticas. Atualmente, a fibromialgia apresenta um diagnóstico como verdadeiras doenças de etiologias ignoradas, apresentando um quadro médico acentuado, constituído de dor por todo o corpo e da síndrome, fadiga recorrente (BALLONE; ORTOLANI; NETO, 2007).

Considerada como uma patologia, a fibromialgia é proeminente por acarretar redução na condição de vida e em permanecer na sociedade universal (2,5 a 5\%) da população. Seus resultados implicam em um choque não somente para o doente, mas para a sociedade, com despesas diretas e indireta (GAVI, 2018).

Gavi (2018) esclarece que, os atrasos cognitivos em doentes podem espontaneamente não ser compreendido por um clínico geral ou desconsiderado de sua avaliação. No entanto, os autores evidenciam queixas gerais de doentes com fibromialgia no campo das funções cognitivas, ressaltando seus desenvolvimentos na dinâmica cotidiana dos portadores.

Para tanto, são identificados enigmas na organização e na idealização de futuro, queixas relacionadas à memória, de localizar termos adequadas ou replicar ligeiramente, desordem mental e concentração. Múltiplas pesquisas propuseram comprometimento cognitivo na doença, compreendendo como queixas de memória e de concentração (GAVI, 2018).

Portanto, os tratamentos utilizados para FM englobam intervenções para tratar e promover a qualidade de vida destas pessoas através da atuação de diversos profissionais de forma multidisciplinar, o que poderá constituir no auxílio para o alívio do sofrimento desses pacientes, fazendo com que os mesmos enfrentam múltiplas dificuldades, entre elas, fatores físico, emocionais e comorbidades. Assim, constituem uma área de estudo repleta de crenças arraigadas e com respostas defensivas (LAVIN, 2014).

Entretanto, a fibromialgia é reconhecida como uma síndrome dolorosa crônica, cujo principal sintoma é a dor muscular difusa, a qual não advém de nenhuma lesão articular ou processo inflamatório, permanecendo por mais de três meses, associada a outros sintomas, como fadiga, sono não reparador, rigidez matinal, constipação ou diarreia, bruxismo, cefaleia, ansiedade e depressão, entre outros (MARQUES, 2015).

Por outro lado, a fibromialgia é uma doença músculo esquelético nos tecidos onde suas principais características se apresentam juntamente associada a alterações na percepção da dor, serotonina cerebral reduzida, anormalidades na microcirculação e no metabolismo energético muscular e padrões de sono anormais (LAVÍN, 2014).

Em presença dos dados, buscou-se reunir informações para responder a seguinte indagação: quais os aspectos da atuação do psicólogo que auxiliam no tratamento de pacientes fibromialgico?

Desta forma, este trabalho apresentou como objetivo geral descrever sob a síndrome de fibromialgia e a contribuição da psicologia neste contexto. Evidenciando os objetivos específicos em identificar o perfil epidemiológicos da população acometida pela síndrome; discutir as causalidades da patologia e apontar as principais teorias e técnicas psicológicas sobre a síndrome Fibromialgica. 
Considera-se a realização deste trabalho bastante oportuno, devido ao baixo números de trabalhos abordando esta temática na área da psicologia. O interesse pelo tema desta pesquisa se deu a partir do olhar enquanto acadêmica de psicologia e principalmente por conviver com uma portadora na família, necessitando assim, o olhar diferenciado no tratamento e acompanhamento psicológico envolvidos no decorrer do processo.

Para tanto, a metodologia adotada para o desenvolvimento deste trabalho foi a revisão de pesquisa bibliográfica nas bases de dados BVS-PSI, SCIELO, buscando artigos científicos no período de 2013 a 2019, sendo, resumos publicados em teses, dissertações, trabalho de conclusão de curso (TCC) e livros.

\section{QUAL A ORIGEM DA FIBROMIOALGIA?}

A fibromialgia tornou-se conhecida em meados da década de 70 por estudiosos daquele tempo que reconheceu a ausência de fenômenos inflamatórios da doença em 1977, assim, o termo fibrosite é substituído por fibromialgia, possibilitando a relação dos critérios diagnósticos da patologia instigando as pesquisas até nos dias atuais (CORDEIRO, 2018).

Os inícios dos registros dessa patologia aparecem em meados do século XIX, ilustrando relatos de vestígios dessa doença desde 1904, estando, manifestada pelo nome de fibrosite. Essa patologia era conjunta da ausência de lamentações e descobertos pelo corpo com dores associadas aos músculos, destacando, questionamentos sobre tal fenômeno, ou dados de outras ordens (CORDEIRO, 2018).

No mesmo momento, outros nomes corriqueiros estiveram presentes: reumatismo psicogênico, fibrosite nodular, miofascite, miofibrosite e mialgia reumática. Exclusivamente entre os anos 70 e 80 sucedeu um aprofundamento de estudos sobre a patologia progredindo em uma ciência fisiopatológica, admitindo uma captação que se tratava de uma patologia generalizada e que possivelmente teria relações com outras doenças (CORDEIRO, 2018).

De acordo com a história da fibromialgia, durante vários séculos ela se apresenta com variadas nomenclaturas, incluído o de fibrosite, a doença era conhecida como um quadro confuso de uma condição clínica comum, somente na década de 80 foi reconhecida como uma síndrome distinta. Dessa forma, o nome fibromialgia tem origem nos termos: fibra do latim (tecido fibroso), mio do grego (referente aos músculos), e algia originário do grego (algos), que significa “dor” (ZANETE, 2014).

Em concordância, Cordeiro (2018) destaca que, os primeiros apontamentos da fibromialgia se dão no início do século XIX quando a mesma foi comumente conhecida como "fibrosite". A FM era associada à ausência de queixas consistentes ou de achados físicos; sua dor era associada aos músculos, se tornando sinônimo de doença idiopática (refere a sintomas ou doenças que não tenham causa definida) motivando questionamentos sobre se de fato se tratava de uma síndrome ou demandas de outra ordem. Diferentes termos comuns à época foram: mialgia reumática, fibromiosite nodular, miofascite, reumatismo psicogênico e miofibrosite.

Para tanto, a fibromialgia é uma patologia reconhecida pelos profissionais, hoje em dia e classificada no código internacional de doenças, CID 10 M79.7, sendo considerada como uma doença grave e incurável.

\section{O QUE É DOR?}

A etiologia da dor é variada, sendo considerada que a mesma se manifesta com sensações subjetivas, aparecendo, medo, divergências psicológicas e se revela na redução da qualidade de vida do portador, juntamente com seus familiares, deixando-os vulneráveis ao sofrimento (FERREIRA, 2014). 
A dor ${ }^{3}$ está no corpo, na mente, na história de vida, no cotidiano, no mundo, sendo integrante da vida e tem a função de proteger a integridade física da pessoa. No entanto, ela pode ser incontrolável e, assim, capaz de afetar as características da vida em seu mundo visível e invisível imposto pela dor (LIMA, 2018).

Acompanhada de lesão real, a dor reflete mudanças na concepção de vida dos portadores, destacando os prejuízos reais no corpo, a possível ameaça, ou alguns termos de tal dano, mesmo não estando no corpo, não sendo visível, é percebido e descrito como estando nele, pelo doente. Assim, a dor é uma vivencia desconfortável, sensível e emocional (SRB, 2018).

O diagnosticado para essa patologia é difícil, considerando os variados aspectos de diversas dores gerais, existindo limite nos passos e ao galgar escadas. Determinados doentes observam os sinais, sendo, "dor por todo o corpo", ou ainda, experimentam dor em diversas partes do corpo e sem ter um ponto definido, impedindo assim, a exatidão da queixa para o clínico. A dor difusa está presente na fibromialgia e faz parte de um dos grupos fundamentados e pertinente em toda parte do corpo, incluindo cansaço e rigidez (BALLONE; ORTOLANI e NETO, 2007).

Presentemente, Gavi (2018) elucida que, o elemento mais acentuado do quadro, a dor, é explicado por irregularidades no Sistema Nervoso Central (SNC), com menos influência de complicações periféricas. Os fatores hereditários, imunológicos, do ambiente como inflamações e estressores são conduzidos em suma importância, proporcionando a síndrome sendo uma patologia com diversos fatores.

Entretanto, o quadro apresenta um complexo diagnóstico decorrente dos diversos sintomas e comorbidades com outras patologias, não existindo exames laboratoriais direcionados, sendo, basicamente o exame clínico, (GAVI, 2018).

Os portadores de fibromialgia apresentam afinidade com variadas queixas de dor, destacando, expressões como: impressão de aumento de peso, fisgada, ardência, dormência e outras. Sendo, difícil localizar o ponto preciso da dor, avaliando que, em alguns casos da doença os pacientes podem sentir a sensação de que a dor "caminha pelo corpo", abrangendo aglomerados músculos. Outros usuários percebem-nas articulações, nos ossos ou nos "nervos", entretanto, é corriqueiro escutar o tema "doutor, tudo doe" (BALLONE; ORTOLANI e NETO, 2007).

Considera-se que, os fatores hereditários, imunológicos, do ambiente como inflamações e estressores são conduzidos em suma importância, proporcionando a síndrome sendo uma patologia com diversos fatores e um complexo diagnóstico decorrente dos diversos sintomas e comorbidades com outras patologias, não existindo exames laboratoriais direcionados, sendo, basicamente o exame clínico, esclarecendo que, o elemento mais acentuado do quadro, da dor, é explicado por irregularidades no Sistema Nervoso Central (SNC), com menos influência de complicações periféricas (TORQUATO, 2019).

No entanto, a Associação Internacional para o Estudo da Dor (IASP) define dor como um conhecimento sensorial e emocional desconfortável decorrente de lesão real ou possível dos tecidos do organismo. Ressalta uma manifestação essencialmente particular, variando sua exposição de indivíduo para indivíduo. É um sinal acentuado, considerado o quinto sinal vital a ser analisado nas consultas médicas (GOLDENBERG, 2014).

Segundo o Manual Diagnóstico e Estatístico de Transtornos Mentais (DSM-V, 2014), para a dor ser considerada aguda, a sua duração deve ser inferior a seis meses e para ser considerada crônica, o período é de seis meses ou mais.

3 “Dor", de acordo com o Dicionário Aurélio on line (2018), significa mágoa, aflição, dó, condolência e remorso. Nucleus,v.16,n.2,out.2019 


\section{O QUE É DOR CRÔNICA?}

A dor ${ }^{4}$ crônica se destaca como um dos sintomas marcantes na síndrome da fibromialgia, trazendo graves complicações a saúde podendo gerar danos à saúde física e mental e não são aptas a um só tipo de tratamento, considerando diversos mecanismos controladores que atuam no sistema nervoso produzindo alterações permanente na vida do portador (CORDEIRO, 2018).

Segundo a Organização Mundial de Saúde (OMS) a dor crônica faz parte da vida de $30 \%$ da população mundial. Somente no Brasil, este número chega a quase 60 milhões de pessoas. Deste total, cerca de $50 \%$ já sofreu algum tipo de comprometimento durante a realização de atividades rotineiras, como no trabalho, sono ou lazer, o que afeta a qualidade de vida e a interação familiar de forma considerável (SBED, 2016).

Atualmente a dor crônica proporciona uma temática de inquietude analisada há claridade de inúmeras compreensões, para tanto, no decorrer dos anos, diversas teorias alcançaram uma maior clareza aos estudos desse acontecimento, estabelecendo uma dicotomia (saúde-patologia) e transtorna o ser humano em ser pensante ilustrando destacando o modelo cartesiano que estabelece um corpo anatomista. Ou seja, um físico explanado pela mente amparando uma relação entre físico e mente ilustrando o controle da dor. Essa abordagem destaca a seriedade efetivada pela espinha medular, hipotálamo e o sistema nervoso central nos processos de dor (CORDEIRO, 2018).

A partir do texto, os autores destacam que, pacientes com fibromialgia possuem dor aguda (leve) $\mathrm{x}$ dor crônica (intensa), proporcionando ao portador tais impedimentos, sendo estas:

Dor aguda (leve):

a) Não dificulta a realização de trabalhos motoras e cognitivas,

b) Não impedem o execução da atividade profissional e social,

c) Não incapacita o cumprimento ocupacional,

d) Não causam impacto no cotidiano e promovem a ruptura da rotina,

e) Não produz impactos sociais, nem desestabilizam entre outros,

E as dores crônicas:

a) Prejudicam na execução da atividade profissional e social,

b) Desencadeia a incapacidade funcional dos doentes refletindo adversamente no desempenho ocupacional,

c) Dificulta a realização de tarefas motoras e cognitivas,

d) Causam impacto no cotidiano e promovem a ruptura da rotina, que tende a se manter ao longo do tempo,

e) Os impactos sociais desestabilizam as relações familiares, restringem o contato social e interferem nos hábitos e rotinas dos doentes.

As alterações referidas acima, explicam que as alterações levam a uma possível desestabilização das relações familiares, assim como a um crescente isolamento social, restringindo os contatos sociais e interferindo nos hábitos e rotinas, forçando os portadores da FM à adaptação dessa nova realidade (CORDEIRO, 2018).

\footnotetext{
${ }^{4} \mathrm{O}$ que não mais se discute é se a dor do paciente é real ou não. Hoje, com técnicas de pesquisa que permitem ver o cérebro em funcionamento em tempo real, descobriu-se que pacientes com FM realmente estão sentindo a dor que referem. Mas é uma dor diferente, onde não há lesão na periferia do corpo, e mesmo assim a pessoa sente dor. Toda dor é um alarme de incêndio no corpo - ela indica onde devemos ir para apagar o incêndio. Na fibromialgia diferente - não há fogo nenhum, esse alarme dispara sem necessidade e precisa ser novamente "regulado" (SITE DA SOCIEDADE BRASILEIRA DE REUMATOLOGIA, 2018).
} 
Para Cordeiro (2018), o fibromialgico, não só experimenta a sensação de dor, mas também se vê forçado a viver com alterações no seu dia a dia provocadas pela limitação das atividades, rupturas de rotinas, mudanças no estado de humor, uma diminuição da energia, distúrbios entre outros e assim necessitando da ajuda multiprofissional.

Em concordância, Goulart; Pessoa; Júnior (2016) enfatizam que, o fibromiálgico, não só experimenta a sensação de dor, mas também se vê forçado a viver com alterações no seu dia a dia provocadas pela limitação das atividades, rupturas de rotinas, mudanças no estado de humor, uma diminuição da energia e distúrbios de sono. Todas estas alterações levam a uma possível desestabilização das relações familiares, assim como a um crescente isolamento social, restringindo os contatos sociais e interferindo nos hábitos e rotinas, forçando os portadores ao ajustamento dessa nova realidade.

Por fim, Cordeiro (2018) esclarece que, a fibromialgia é uma síndrome crônica que necessita de manutenção em grande parte para diminuir as dores sentidas por todo o corpo durante longos períodos, com sensibilidade nas articulações, nos músculos, tendões e em outros tecidos moles pelos acometidos por ela e está diretamente ligada também à fadiga, distúrbios do sono, dores de cabeça, depressão e ansiedade.

\section{PERFIL EPIDEMIOLOGICO}

Nos últimos tempos, a compreensão da Síndrome de Fibromialgia (SFM), modificou espantosamente. Anteriormente era avaliado como um transtorno discreto, no entanto, sobreveio a ser vista como o fim de um continuum, em uma representação que conglomera aspectos clínicos de dor incurável e generalizada, seguida de sintomas psicossomáticos, de fadiga, alterações no sono, no humor, dificuldades de memória e outros (GAVI, 2018).

Torquato (2019) destaca que ao mesmo tempo que, portadores de Fibromialgia proporcionam maior número de gordura e menor indicador de massa de lipídio em comparação à sociedade como um todo, situação em que aguça um agravo da irritabilidade à dor e, em resposta, do padrão de vida destes portadores.

Entretanto, portadores de Fibromialgia proporcionam maior número de gordura e menor indicador de massa de lipídio em comparação à sociedade como um todo, situação em que aguça um agravo da irritabilidade à dor e, em resposta, do padrão de vida destes portadores (TORQUATO, 2019).

Para tanto, Torquato (2019) explica que, a fibromialgia se localiza intimamente conexa com a depressão e com outros distúrbios, o que possivelmente pode provocar em alterações, de tal modo, há prováveis aparecimentos da afinidade entre a obesidade e a fibromialgia como um fator psicológico avaliado como doença. Contudo, não é possível confirmar se a obesidade constituiria em uma causa ou resultado das funções anormais ou patológicas dos vários órgãos e aparelhos do organismo.

Analisando o exposto, a avaliação confiável da condição nutricional e a quantidade dos elementos corporais destacam-se imprescindíveis para quantificar os membros do corpo, assim, como envolver os benefícios da dieta, da atividade física, da fibromialgia e do estado físico, dentre outros dados ambientais que beneficiam o corpo humano (TORQUATO, 2019).

\section{QUAL A PREVALENCIA?}

A Fibromialgia (FM) é uma patologia incurável qualificada por dores musculares generalizada prolixa, cansaço e dificuldade no sono, o que acarreta prejuízo físico, psicológico aos seus usuários. Entretanto, existe uma etiologia pouco conhecida e comumente ataca mulheres na faixa etária entre 35 a 60 anos de idade (TORQUATO, 2019). 
Entretanto para Ballone (2007), a incidência da fibromialgia prevalece entre $4 \%$ a $15 \%$ da população, exaltando uma taxa de $73 \%$ dos episódios diagnosticados para o sexo feminino destacado em uma faixa etária entre 29 e 37 anos de idade.

Em relação aos fenômenos da fibromialgia, considerando as áreas das doenças psicossomáticas ${ }^{5}$ enquanto há uma posição igualmente bem definida de muitos profissionais da saúde assim como muitos pacientes que não associam a dor física com a dor emocional desconsiderando por exemplo, a relação da dor FM com a depressão causando maior sofrimento, podendo levar o paciente ao isolamento social com privação de cuidados; afetar a adesão ao tratamento; a eficácia dos analgésicos e desesperança (ZANETE, 2014).

A prevalência de depressão e outras anormalidades psicológicas são elevadas na síndrome fibromialgia, destacando entre $49 \%$ a $80 \%$, e que estes pacientes apresentam pior qualidade de vida em relação a outras populações com doenças crônicas por exemplo: o câncer, a artrite reumatoide e outros (GOULART; PESSOA; JÚNIOR, 2016).

Para Lima (2018), a prevalência da fibromialgia em idosos, segundo estudo Americano, é de $5,4 \%$, na faixa etária acima de 60 anos e em estudo francês a prevalência foi de $2,8 \%$ e $4,1 \%$; entre as faixas etárias de 65 a 74 anos e 75 a 84 anos, respectivamente. No Brasil foi encontrada na faixa etária de 55 a 74 anos a prevalência de $1,9 \%$ indivíduos idosos com FM.

Por outro lado, Nóbrega (2014) constata em sua pesquisa, outras comorbidades presentes na FM, sendo, sintomas depressivos, que estão entre o mais frequentes em pacientes desta síndrome, estes sintomas comprometem a qualidade de vida dos pacientes ao aumentar a sensação de dor e incapacidade. Assim, esses fatores se tornam os sintomas depressivos mais intensos e devem ser controlados por meio de tratamentos para garantir melhora na qualidade de vida dos portadores.

Cordeiro (2018) destaca a dificuldade de os profissionais pensar fora do dualismo psicofísico. Descreve ainda que a clínica médica prioriza o polo sensorial em detrimento do emocional e assim, acaba por descuidar das esferas emocionais, psicoafetivas, históricas e relacionais que fazem parte do adoecimento.

\section{CAUSALIDADE}

De um modo geral, Oliveira (2018) esclarece que a fibromialgia se apresenta como uma síndrome de causa ignorada fundamentalmente apresentando como especialidade a dor crônica universal e seu aparecimento populacional é rotineiramente no sexo feminino. No entanto, essa patologia se encontra considerada como um tipo de dor disfuncional que aborda o sistema nervoso somático sensitivo e desse modo há hipótese de estar acompanhada à um desajustamento do sistema nervoso central.

Goulart (2016) ressalta que a fibromialgia não apresenta cura, assim como não possui uma única causa. Seus sintomas se manifestam de forma abrangente e persistente, destacando três aspectos etiológicos, sendo eles:

a) Fatores biomecânicos, os quais podem ser estruturais como exemplos: traumas na musculatura esquelética, pernas curtas, hipermobilidade, características posturais, etc.,

b) Fatores bioquímicos incluindo características endócrinas, toxicidade adquirida ou autogerada, deficiências nutricionais, infecção, alérgicas e outros fatores),

c) Fatores psicossociais: consequências de abusos na infância, traços de depressão ou ansiedade, desânimo, solidão, medo, etc.

\footnotetext{
${ }^{5} \mathrm{O}$ termo psicossomático, na expressão mais comum, pode reportar-se tanto ao quesito da origem psicológica de determinadas doenças orgânicas, quanto às repercussões afetivas do estado de doença física no indivíduo, como até confundir-se com simulação e hipocondria, onde toma um sentido negativo (OLIVEIRA, 2015).
} 
Portanto, esses fatores necessitam do acompanhamento multiprofissional. A FM divide-se em primária e secundária, no entanto, a causa é desconhecida na forma primária, podendo ser definida por infecções, estresse, inflamações, traumas etc. e na secundária advém uma condição primária, como por exemplo o hipotireoidismo que concomitantemente desencadeia a fibromialgia podendo desaparecer com o tratamento da causa primária (ZANETE, 2014).

\section{DOENÇAS PSIQUICAS RELACIONADAS}

Entre as causas da fibromialgia existem várias hipóteses prováveis, para Oliveira (2015) doentes com dor crônica apresentam prevalência elevada de transtornos depressivos, ansiosos e transtornos da sexualidade, transtornos do sono, transtornos relacionados com o uso de substâncias, transtornos factícios, transtornos da ansiedade, transtornos conversivos, hipocondria e simulação entre outros.

Torquato (2019) esclarece que a fibromialgia se localiza intimamente conexa com a depressão e com outros distúrbios, o que possivelmente pode provocar em alterações, de tal modo, há prováveis aparecimentos da afinidade entre a obesidade e a fibromialgia como um fator psicológico avaliado como doença. Contudo, não é possível confirmar se a obesidade constituiria em uma causa ou resultado das funções anormais ou patológicas dos vários órgãos e aparelhos do organismo.

Os sintomas da fibromialgia dificultam as estratégias de enfretamento do paciente, reforçando o sentimento de incapacidade. Assim, a depressão ou a ansiedade podem iniciar ou perpetuar os sintomas da fibromialgia e suas características podem manifestar sentimento de culpa, fadiga, vitimização e baixa autoestima (OLIVEIRA, 2015).

De forma geral, os sintomas da fibromialgia dificultam as estratégias de enfretamento das pacientes a se relacionarem com no contexto das dores fibromioalgica permanecendo reforçando o sentimento de incapacidade. Assim, a depressão ou a ansiedade podem iniciar ou eternizar-se os sintomas da fibromialgia e suas características podem manifestar sentimento de culpa, fadiga, vitimização, baixa autoestima e outras (OLIVEIRA, 2015).

Dessa forma, Rodrigues (2017) explica que em meados do ano de 1660, o termo depressão, em inglês, foi empregado para apontar o comportamento desanimado, e posteriormente no século XIX, a palavra entrou para o uso universal. Assim, a depressão pode ser um sinal universal a diversos distúrbios emocionais e por uma longa temporada a depressão se encontra classificada nos critérios de diagnostico, entretanto, somente há poucos anos ela não é considerada como frescura, mas sim qualificada como uma patologia respeitada.

Da mesma forma Torquato (2019) esclarece que a fibromialgia se localiza intimamente conexa com a depressão e com outros distúrbios, o que possivelmente pode provocar em alterações, de tal modo, há prováveis aparecimentos da afinidade entre a obesidade e a fibromialgia como um fator psicológico avaliado como doença. No entanto, não é possível confirmar se a obesidade constituiria em uma causa ou resultado das funções anormais ou patológicas dos vários órgãos e aparelhos do organismo.

Presentemente Rodrigues (2017) esclarece que, as síndromes depressivas são descritas como uma patologia que sinalizam dificuldades no cotidiano das pessoas e que pode ser compreendida como uma condição afetiva (tristeza) ou como uma síndrome, podendo aparecer em diversos casos clínicos como: fibromialgia, transtorno de estresse pós-traumático, alcoolismo, esquizofrenia, demência e doenças clínicas, sucedendo possíveis respostas as condições desafiadoras da vida, social, econômica e afetiva.

Da mesma forma, a evidencias que sinalizam que a depressão ao mesmo tempo pode ser qualificada como mudança de humor, tristeza, irritabilidade, falta de capacidade de sentir prazer ou apatia, podendo se apresentar em situações cognitivas, psicomotoras e vegetativas (sono e apetite) e como doença 
ela pode ser considerada em formatos variados como: Transtorno Depressivo Maior, Melancolia, Distimia, Depressão Integrante do Tipo Bipolar I e II, Depressão como parte da Ciclotimia, entre outras (RODRIGUES, 2017).

Sua abrangência entre as causas da fibromialgia existem várias hipóteses prováveis, para Oliveira (2015) doentes com dor crônica apresentam prevalência elevada de transtornos depressivos, ansiosos e transtornos da sexualidade, transtornos do sono, transtornos relacionados com o uso de substâncias, transtornos factícios, transtornos da ansiedade, transtornos conversivos, hipocondria e simulação entre outros.

Em sua totalidade, a relação entre a fibromialgia e a depressão podem manifestar em dois modelos, no formato primário ela se destaca quando um episódio depressivo encaminha o doente a um quadro reativo a patologia e, nesta condição a enfermidade seria uma contra-ataque da classe depressiva, sucedendo de ordem somática ou secundária quando a patologia contribui para a pessoa manifestar a depressão no organismo (RODRIGUES, 2017).

Além disso, estudos apontam em sua abrangência que amplo problema entre as doentes com fibromialgia ocorrem em prol de perceberem seus próprios sentimentos, acrescendo um índice maior de sintomas no aumentando das dores. As portadoras de fibromialgia evidenciam em suas vivencias um momento negativo evidenciando a qualidade de vida no aumento aos níveis de picos estressores, ocorrendo a maior parte do tempo considerando os fatores históricos arraigados no desempenho da mulher no contexto social e consideravelmente por fatores biológicos do próprio sexo, bem como, fatores hormonais, cuidados caseiros, zelo pela família, período pré-menstrual e outros (RODRIGUES, 2017).

\section{TRATAMENTO}

O tratamento da FM permanece ainda voltado às manifestações clínicas, objetivando o alívio da dor, a melhora da qualidade do sono, o equilíbrio emocional e a diminuição da fadiga, através de medidas farmacológicas e não farmacológicas. A estratégia para o tratamento ideal da FM requer uma abordagem multidisciplinar, com a combinação de diversas modalidades terapêuticas e o tratamento deve ser elaborado em discussão com o paciente, de acordo com a intensidade da sua dor e funcionalidade do mesmo (SILVA, 2018).

Para Fernandes (2013), em relação ao tratamento farmacológico, está indicado o uso de antidepressivos tricíclicos (como a amitriptilina e a ciclobenzaprina); os bloqueadores seletivos da recaptação de serotonina (como a fluoxetina); os benzodiazepínicos (como o alprazolan) e os analgésicos (como o paracetamol e a dipirona).

No que tange ao tratamento não medicamentoso, o exercício físico é de extrema importância e deve fazer parte do tratamento do portador de FM, já que a atividade física proporciona efeito analgésico, estimulando a liberação de endorfinas, proporcionando sensação de bem-estar global. Dentre os exercícios mais indicados está a atividade aeróbica de baixo impacto, como hidroterapia, natação e caminhadas. O suporte psicológico, através das diversas abordagens tem se mostrado efetivo no tratamento destes pacientes, considerando que pacientes com FM apresentam distúrbios psiquiátricos concomitantes em sua maioria (GOLDENBERG, 2014).

No entanto, Lima e Cordeiro (2018) e Rocha (2013) destaca que, em relação aos distúrbios psiquiátricos desenvolvidos por grande parte dos pacientes portadores de fibromialgia, alguns autores afirmam que, pelo fato da FM estar associada à fadiga generalizada, distúrbios do sono, rigidez matinal, dispnéia, ansiedade e alterações no humor, estes sintomas, na maioria dos casos, podem evoluir para um quadro de depressão, afetando negativamente a qualidade de vida dos indivíduos portadores desta doença. 
Entretanto, Silva (2018) esclareceu que os pacientes com fibromialgia têm pior qualidade de vida e níveis mais altos de depressão quando comparados com pessoas sem esta patologia e, sugerem a existência de uma estreita relação entre fibromialgia e depressão e que esta pode ser considerada um sintoma secundário da fibromialgia.

Existe um tripé medicamentoso para o tratamento da fibromialgia, baseando em atividade física regularmente, acompanhada por profissionais especializados, levando o portador a construir práticas saudáveis que colaboram para a diminuição da dor ${ }^{6}$. Para os autores, a educação em saúde se destaca como primordial na qualidade de vida do doente, conscientizando a aceitar suas limitações e a manutenção do manejo necessário (MARQUES, 2015).

No entanto, o diagnóstico é realizado pelo reumatologista, sendo iniciado o tratamento medicamentoso e a psico educação e se necessário, o encaminhamento ao psiquiatra para avaliar possíveis transtornos ou ainda ao fisioterapeuta e principalmente o psicólogo afim de conscientizar o paciente a aceitar suas possíveis limitações bem como, as mudanças do cotidiano. Assim, destacam-se como primordial na qualidade de vida do doente, a equipe multiprofissional, principalmente, o terapeuta e o apoio da família.

Sobre os benefícios do exercício físico em pacientes com fibromialgia, destaca-se a aeróbica podendo ser prescrita para todos os portadores evidenciando a diminuição da dor nos pontos especificos, bem como, a ansiedade, a depressão e outros aspectos emocionais e psicologicos no auxilio da busca constante de recursos internos, bem como, no planejamento das estratégias de enfrentamento propondo uma investigação constante do próprio corpo e do autoconhecimento (SILVA, 2018).

De tal modo, a fisioterapia é um tratamento que desempenha um papel extraordinário, destacando as instruções de exercícios físicos, inserindo fortalecimento muscular, alongamentos, hidroterapia e outros. As atividades com menor intensidade são mais eficazes na proporção de um menor impacto da dor FM na condição de vida dos pacientes (ZANETE, 2014).

Acerca do tratamento farmacológico para a FM, Fernandes (2013), destaca o uso da medicação visando amenizar a dor proporcionado uma maior qualidade no sono dos portadores. Também é associado ao tratamento não farmacológico apresentando a mesma finalidade, acompanhado de atividades físicas, técnicas de relaxamento e principalmente a psicoterapia ${ }^{7}$, benéfica aos episódios do pânico, depressão, ansiedade e outros que surgirem proeminentes.

Entretanto Silva (2018) explica que as medicações mais utilizadas no alívio da dor são: tramadol, morfina e meloxian. O tramadol é um dos medicamentos de uso importante na fibromialgia, pois, além de sua ação como opioíde, ele oferece um discreto bloqueio na recaptação de serotonina, útil nos distúrbios do humor tão comuns na FM. Destaca-se também o medicamento meloxicam sendo um anti-inflamatório que tem uma forte função e age como analgésico podendo ser substituído pelo anti-inflamatório ibuprofeno.

A morfina é um fármaco narcótico do grupo dos opióides, que é usado no tratamento sintomático da dor e está presente no ópio sendo capaz de reduzir a sensibilidade da dor, da fadiga crônica, bem como, a artrite reumatoide. Alguns desses medicamentos trazem efeitos colaterais com diversas reações que

\footnotetext{
${ }^{6}$ A Portaria GM/MS n. ${ }^{\circ}$ 1.319, de 23 de julho de 2002, que inaugura o Programa Nacional de Assistência à Dor e Cuidados Paliativos, surgiu na intenção de desenvolver, entre outras coisas, iniciativas governamentais e não governamentais que contemplem pacientes com dor e em paliação; incentivar e organizar serviços públicos de assistência; desenvolver diretrizes assistenciais nacionais, devidamente adaptadas/adequadas à realidade brasileira. $\mathrm{O}$ objetivo é oferecer cuidados mais humanizados e que contemplem de forma mais integralizada os cuidados à saúde de pacientes com dor e/ou sintomas relacionados a doenças fora de alcance curativo (CORDEIRO, 2018).

7 A principal prioridade no tratamento da dor crônica é ensinar o paciente a enfrentar e reduzir a dor e, em um segundo momento, ensiná-lo a empregar as técnicas cognitivas para rebater as crenças que destroem sua aceitação da responsabilidade no emprego de técnicas de enfrentamento e autogerenciamento (BECK, 2013).
}

Nucleus,v.16,n.2,out.2019 
podem afetar o dia a dia de maneira intensa, levando a modificação de seus hábitos radicalmente. No entanto, alguns desses medicamentos trazem efeitos colaterais com diversas reações que podem afetar seu dia a dia de maneira intensa, levando a modificação de seus hábitos radicalmente (SILVA, 2018).

Em concordância os autores Lima; Silva; Cordeiro (2018); Rocha (2013) propõe um olhar diferenciado da família e dos profissionais afim de compreenderem a dinâmica de cada portador, em seu meio social, cultural e econômico, reconhecendo as estratégias e adotando cuidados adequados para o doente, amenizando os impactos da dor e interagindo mutuamente na dinâmica familiar.

\section{INTERVENÇÕES FARMACOLOGICAS}

De forma geral, o tratamento farmacológico prossegue como componente comum na maior parte dos episódios de fibromialgia. Múltiplos fármacos estiveram agregados a fim de controlar os sinais da dor presentes na patologia. Entretanto, em hipóteses os antidepressivos são os mais empregados na manutenção da doença, bem como, no tratamento. Assim, se encontram os tricíclicos, a amitriptilina sendo um dos medicamentos que reúnem mais conhecimento na literatura, bloqueando a recaptação de tal maneira da noradrenalina como de serotonina, consistindo em princípios moduladores e geradores de analgesia central (OLIVEIRA, 2018).

Da mesma forma, Oliveira (2018) esclarece que sua condição de indicação entre diretrizes é superior, com intenção a se nortear doses inferiormente de $50 \mathrm{mg} / \mathrm{dia}$ com evolução não exclusivamente da dor, mas, como de sono e agitação. No entanto, existe um perfil com diferentes implicações, compreendendo o aumento do peso, moleza excessiva e prováveis agitações de elementos presentes na consciência, especialmente, em pessoas com maior idade que se encontram propensos nas limitações fase e para o uso satisfatório da amitriptilina, evidenciando custo inferior com posologia correspondente.

Em sua totalidade, a ciclobenzaprina, apresenta uma composição parecida à amitriptilina, analisada ao mesmo tempo como tricíclico. No entanto, a ciclobenzaprina se constituiu, primeiramente, distribuída como um fármaco de efeito antipsicótico; e, presentemente, sua descrição mais frequente apresenta como recomendação na atuação central e como relaxante muscular. Para tanto, em observações aos pacientes fibromiálgico esse fármaco elevou à um quadro significativo de evolução das queixas de dores considerando (em cada cinco pacientes de dez) acompanhados de amitriptilina uma dose de 1 a $4 \mathrm{mg}$ no período noturno comprovando um sono de maior qualidade (OLIVEIRA, 2018).

Comumente isso acontece porque os inibidores da recaptação de noradrenalina e serotonina, ao mesmo tempo são destacados como inibidores duais, de maneira parecida aos tricíclicos e causam analgesia central por ação em vias nervosas inibitórias descendentes apresentando uma evolução no quadro dos pacientes com fibromioalgica. Para tanto, a duloxetina é um dos fármacos desse contexto que proporciona maiores resultados no tratamento dessa patologia, frequentemente em dose de $60 \mathrm{mg} / \mathrm{dia}$, de maneira especial, seguida nos quadros de ansiedade ou não, permanecendo associação de morbidade depressiva (OLIVEIRA, 2018).

\section{TEORIAS E TÉCNICAS PSICOLÓGICAS}

Os autores destacam a seriedade do conhecimento sobre a FM, destacando a importância do psicólogo junto ao tratamento do portador da síndrome e sua família, no esclarecimento da doença, suas complicações, considerando que possivelmente o portador possa se fazer de vítima negando o seu sofrimento ou maximizando sua dor em prol de um benefício próprio (LIMA, 2018; CORDEIRO, 2018; ROCHA, 2013). 
Em concordância, Cordeiro (2018) destaca que, há um número elevado de pacientes diagnosticados com a FM, porém, uma preocupação em relação ao diagnóstico correto, evidenciando que, falsas avaliações podem acarretar danos para o paciente, a família e a sociedade em geral, incluindo os benefícios de afastamento do trabalho elevando gastos públicos.

Após a manifestação clínica ${ }^{8}{ }^{9} \mathrm{da} \mathrm{FM}$, o diagnóstico é realizado pelo médico especialista em fibromialgia, o reumatologista, sendo iniciado o tratamento medicamentoso e a psico educação, afim de explicar sobre a síndrome e se necessário, o encaminhamento ao psiquiatra para avaliar possíveis transtornos e principalmente o psicólogo (GOLDENBERG, 2014).

Para Cordeiro (2018), a psicoterapia permite aos portadores compreender as implicações psicológicas, as atividades físicas, o efeito dos fármacos em processo contínuo principalmente visando o benefício de uma melhor qualidade de vida.

O acompanhamento do psicólogo durante o tratamento de um portador da síndrome de fibromialgia, contribui no esclarecimento sobre a doença e suas complicações aos seus cuidadores e familiares, informando sobre a possível negação do doente, a respeito da síndrome, como também a maximização da sua dor em prol de um benefício próprio (CORDEIRO; SILVA, 2018).

O estresse psicológico pode ser definitivo no desenvolvimento da FM, Entretanto, do ponto de vista terapêutico, não é útil caracterizar a fibromialgia como sendo um problema puramente psicológico ou puramente orgânico (NOBREGA, 2014).

A psicoeducação funciona como uma técnica importante na intervenção em pacientes portadores FM, proporcionando alivio das dores, autonomia, confiança, resgatando autoestima e estratégias de enfrentamento da dor, além de permitir ao sujeito um manejo caracterizado em lidar com circunstâncias concretas, ansiedade, estresse.

A Psicoeducação é uma técnica que se baseia na explicação de questões importantes do tratamento psicológico ao paciente. Ela deve ser feita da forma mais simples e didática possível, de acordo com a linguagem de cada paciente. A psicoeducação trata tanto de dados sobre o diagnóstico quanto de explicações sobre as atividades que são utilizadas durante as sessões.

O Registro de pensamentos disfuncionais é outra atividade muito comum na terapia cognitivocomportamental. Como o foco da abordagem é a relação entre pensamento e comportamento, é essencial identificar os elementos disfuncionais. Ao utilizar essa técnica, o terapeuta pede que o paciente registre os pensamentos desagradáveis que surgem em determinadas situações (MARQUES, 2015).

Desta forma, o paciente se percebe como um todo, um ser dinâmico e complexo com diversas grandezas: física, afetiva, cognitiva e comportamental, assim a contribuição do profissional na área de psicologia, necessitará ser pautada e teoricamente fundamentada no modelo biopsicossocial auxiliando no processo da dor constante, no ajustamento dos fármacos, bem como, angustias, medos e frustrações (LIMA, 2018).

Com a regulação dos níveis emocionais e relacionais, os pacientes tendem a terem a dor física e emocional minimizada. A psicoterapia lhes permite obter uma maior qualidade de vida e melhoras nos

\footnotetext{
${ }^{8}$ As manifestações clínicas presentes na história particular de cada paciente (sono não reparador, cefaleia, dores, depressão, ansiedade, queixas gástricas, intestinais, urinárias, genitais, etc.) são expressão simbólica do quadro psíquico, e são tão discrepantes, vagas e incaracterísticas, que se torna insensato acreditar simplesmente em organicidade (OMS, 2018).

9 A Portaria GM/MS n. ${ }^{\circ}$ 1.319, de 23 de julho de 2002, que inaugura o Programa Nacional de Assistência à Dor e Cuidados Paliativos, surgiu na intenção de desenvolver, entre outras coisas, iniciativas governamentais e não governamentais que contemplem pacientes com dor e em paliação; incentivar e organizar serviços públicos de assistência; desenvolver diretrizes assistenciais nacionais, devidamente adaptadas/adequadas à realidade brasileira. $\mathrm{O}$ objetivo é oferecer cuidados mais humanizados e que contemplem de forma mais integralizada os cuidados à saúde de pacientes com dor e/ou sintomas relacionados a doenças fora de alcance curativo (CORDEIRO, 2018).
}

Nucleus,v.16,n.2,out.2019 
seguintes aspectos (CORDEIRO, 2018).

a) Aceitar a dor e conviver com ela,

b) Restabelecer o equilíbrio emocional,

c) Aumentar a qualidade do sono,

d) Melhorar os relacionamentos com os outros, especialmente com a família (que vive mais perto do sofrimento e dos efeitos da dor da síndrome da fibromialgia).

O psicólogo pode auxiliar e informar no esclarecimento desta síndrome e sobre as limitações que este impõe, junto a familiares e pessoas significativas. Assim como a família pode não reconhecer o desconforto do paciente, pode também supervalorizá-lo; o paciente pode por sua vez, apresentar o mesmo movimento, maximizando a sua dor por conveniência, fazendo-se de vítima, ou, revoltando-se por não sentir o seu sofrimento respeitado (SILVA, 2018).

Assim, os tratamentos psicológicos podem incluir uma variedade de abordagens tais como psicoterapia, aconselhamento, gerenciamento da dor e estresse, relaxamento, estratégias de reação e outras técnicas. Uma a uma das intervenções psicológicas e da terapia de grupo podem ser empregadas para ajudar os pacientes a desenvolver melhores mecanismos de enfrentamento e aprimorar suas perspectivas, assim, o psicologo que acompanha o doente, precisa orientar os familiares, tirar as dúvidas, explicar como a doença acontece e de como o paciente precisa desse apoio familiar ${ }^{10}$ (GOLDENBERG, 2014).

\section{INTERVENÇÃO PSICOTERAPICA}

As terapias analíticas atuam de qual modo? De uma maneira universal é considerada uma abordagem interrogativa, tendo como finalidade em provocar o paciente a pensamentos com possíveis comprovações, desacordo e consentimentos. Essa teoria aborda alguns fatores terapêuticos que não se balizam exclusivamente às costumadas explanações que gerem aos imprescindíveis insights. A "pessoa real do analista" para o paciente como um modelo respeitável de identificação e assim, de forma mais aparente ou intensa, é importante instigar a capacidade para o paciente fazer reflexões conscientes (ZIMERMAN, 2008).

Atualmente, as práticas psicanalíticas necessariamente deixaram de ser analisadas como um "nome feio" e podem ser empregadas como um extraordinário meio de compreender como o doente está transmitindo elementos que ele ainda não alcança para adentrar em contato. Taís dificuldade se encontram presentes nas possíveis causas que geram ações, sendo, a de que ele não alcança acuradas dores aflitivas, rememorar, refletir, verbalizar e reprimir. Assim, o analista estará contribuindo para o paciente desenvolver a aprender com as próprias vivencias (ZIMERMAN, 2008).

Para Zimerman (2008) em analise a cura analítica jamais será integral, em concordância com Freud, para deliberarmos as infelicidades neuróticas, mas nunca os adversidades da vida. O admirável é que tenha existido no paciente um expressivo desenvolvimento espiritual e intelectual, um crescimento do ego, de maneira satisfatória para encarar as instabilidades habitual da vida, além de abrir os olhos para uma emoção de livre-arbítrio, alcance de habilidades, de capacidade criadora e aluição de contentamentos de prazer, bem como, as construções do vínculo que se constitui entre paciente e analista.

De forma geral, na Psicanálise, o primeiro contato com o paciente segue de uma "entrevista inicial", seguido da escuta analítica, a meta do procedimento psicanalítico é ressignificar a história do paciente, o que equivale a uma ressignificação dos fatos, sendo que a substituição do significado arrasta

\footnotetext{
${ }^{10} \mathrm{Na}$ literatura cognitivo-comportamental, a principal prioridade no tratamento da dor crônica é ensinar o paciente a enfrentar e reduzir a dor e, em um segundo momento, ensiná-lo a empregar as técnicas cognitivas para rebater as crenças que destroem sua aceitação da responsabilidade no emprego de técnicas de enfrentamento e autogerenciamento (GOLDENBERG, 2014).
}

Nucleus,v.16,n.2,out.2019 
consigo uma magnitude de afeto suficiente para dar-lhe significância (NOBREGA, 2014).

A reconstituição histórica e cronológica e integração entre datas, acontecimentos e eclosões somáticas também seria parte do trabalho do analista em casos como a fibromialgia, assim, acompanhamentos psicoterápicos podem ser uma alternativa no tratamento da FM, auxiliando na convivência com a dor, dentre outros sintomas que a síndrome remete ao portador (NOBREGA, 2014).

Desta forma Nobrega (2014) esclarece que a tarefa do analista com os pacientes psicossomáticos ${ }^{11}$ a compreensão da dificuldade desses pacientes em nomear seus estados afetivos e um papel mais ativo por parte do analista, de modo que a atividade interpretativa permita o uso de clareamentos, confrontos, assinalamentos e o emprego de perguntas que estimulem o paciente a fazer reflexões.

$\mathrm{Na}$ Psicanálise, a meta do procedimento psicanalítico é ressignificar a história do paciente, o que equivale a uma ressignificação dos fatos, sendo que a substituição do significado arrasta consigo uma magnitude de afeto suficiente para dar-lhe significância. A reconstituição histórica e cronológica e integração entre datas, acontecimentos e eclosões somáticas também seria parte do trabalho do analista em casos como a fibromialgia, assim, acompanhamentos psicoterápicos podem ser uma alternativa no tratamento da FM, auxiliando na convivência com a dor, dentre outros sintomas que a síndrome remete ao portador Nobrega (2014).

Para Nobrega (2014), a tarefa do analista com os pacientes psicossomáticos ${ }^{12}$ a compreensão da dificuldade desses pacientes em nomear seus estados afetivos e um papel mais ativo por parte do analista, de modo que a atividade interpretativa permita o uso de clareamentos, confrontos, assinalamentos e o emprego de perguntas que estimulem o paciente a fazer reflexões.

\section{TEORIA COGNITIVO COMPORTAMENTAL}

Atualmente, como sucede o manejo na Terapia Cognitivo-Comportamental? O modelo encontrado na Terapia Cognitivo-Comportamental se destaca com ênfase nos elementos cognitivos, afetivos e comportamentais no desenvolver-se da dor crônica e na manutenção. Diversas técnicas são instruídas aos clientes como enfrentamento dos acontecimentos de dor, como reconstrução cognitiva, táticas de enfrentamento e técnicas de relaxamento, bem como, o treinamento na diminuição de sentimentos de abandono e falta de domínio em constituir maior domínio sobre a dor (OLIVEIRA, 2018).

De forma geral, o enfoque dessa abordagem se destaca nos treinamentos para melhorar o controle cognitivo e comportamental da fibromialgia, assim, recentemente têm sido empregados diversos manejos técnicos demonstrando modificar o processamento encefálico da dor por meio da terapia, vivenciando vinculações modificadas entre sinais de dor, emoções e cognições. Taís técnica mostrou-se útil no manejo em curto e médio prazo da fibromialgia, principalmente, se associada ao acompanhamento multidisciplinar (SILVA, 2018).

Desta forma, Rodrigues (2017) destaca que a Terapia Cognitivo Comportamental (TCC), apresentou seu princípio na década de 1960 desenvolvida por Aaron Beck, oferecendo modelos daquele tempo como uma sugestão nova de psicoterapia. Proposta está composta de períodos com pequena duração direcionando à atualidade (BECK, 2013). De acordo ainda com Rodrigues (2017), essa abordagem apresenta como alvo no tratamento a dor crônica, levando o doente ao autoconhecimento, o

11 Cada doença é psicossomática, uma vez que fatores emocionais influenciam todos os processos do corpo, através das vias nervosas humorais e que os fenômenos somáticos e psicológicos ocorrem no mesmo organismo e são apenas dois aspectos do mesmo processo (NOBREGA, 2014).

12 Cada doença é psicossomática, uma vez que fatores emocionais influenciam todos os processos do corpo, através das vias nervosas humorais e que os fenômenos somáticos e psicológicos ocorrem no mesmo organismo e são apenas dois aspectos do mesmo processo (NOBREGA, 2014).

Nucleus,v.16,n.2,out.2019 
pensamento sobre como encarar e diminuir a dor, e em seguida, informar o manejo que a psicoterapia cognitiva pode amparar frente à dor.

Da mesma forma, o tratamento advém primeiro por meio de uma avaliação, que incide em apanhar dados sobre os sintomas, bem como, o levantamento histórico da doença, assim como fatos importantes da vida do portador, neste início devem ser aplicados questionários que irão levantar dados significativos da dor (RANGÉ, 2001). Entretanto, a Sociedade Brasileira de Reumatologista em (2011) elaborou uma cartilha para informar aos portadores de fibromialgia sobre o manejo da psicoterapia na Terapia Cognitivo Comportamental apresentam resultados em curto espaço de tempo com grande eficácia proporcionando aos clientes juntamente com outros tratamentos, formando assim uma equipe multidisciplinar (RODRIGUES, 2017).

Rangé (2013) destaca que:

A terapia cognitivo-comportamental (TCC) tem sido muito utilizada no manejo da dor, sendo considerada a base de muitos programas de controle da dor e mostrando se eficaz em diferentes programas. Intervenções psicoeducativa com enfoque cognitivocomportamental incluem educação sobre dor, estímulo à autoconfiança, estabelecimento de metas, estabelecimento de ritmo para as atividades, treino de estratégias de coping, técnicas de relaxamento, reestruturação cognitiva, técnicas de resolução de problemas, modificação de comportamentos dolorosos e prática de exercícios (RANGE, 2013).

Em sua totalidade, Rodrigues (2017) esclarece que as táticas e os manejos da dor mencionadas por Rangé (2013) compreendem que o conhecimentos dos resultados adquiridos na primeira análise proporcionará toda a continuidade do tratamento oferecendo seguida da ressalva detalhada da inicial fase, a análise, tendo aspectos depressivos ou não sugerirá quais caminhos necessitarão ser percorridos. Em continuidade Rodrigues (2017) destaca que, a teoria das técnicas de relaxamento contínuo ajudará a impedir doenças musculares, bem como, o controle das tensões no auxilio e alivio da dor proporcionando um quadro menor de ansiedade e assim contribuindo para uma maior qualidade do sono e outros benefícios:

a) Engajamento em exercícios de lazer e sociais: tendo como finalidade levar o paciente à mudança do foco da dor para diferentes situações mais prazerosas, sendo, um dos papéis do terapeuta incentivar o doente,

b) Concretização de atividade física: tendo como finalidade o fortalecimento da musculatura, bem como, favorecendo o tônus muscular na contribuição para a diminuição da dor e animar o portador para a atividade pode acrescentar provisoriamente a dor em benefício do músculo estar fraco, no entanto, logo que este fortifique a dor diminuirá,

c) Reforço diferencial da conduta adequada: ajudará o paciente a se motivar para o tratamento, sempre que o paciente demonstrar um comportamento que não seja de fuga ou esquiva, sugerese reforça-lo,

d) Desenvolver habilidades sociais e treino assertivo: procurando animar o doente a verbalizar sobre suas emoções levando-os a buscar inclusão em outros grupos, bem como, novos contextos sociais renovando seus objetivos emocionais em lidar com a dor,

e) Distração: incide em levar o portador a olhar ao seu meio e procurar focar em diferentes acontecimentos que sucessivamente gostava e propor por músicas de seu estilo a fim de realizar exercícios que lhe proporcionem satisfação ajudando gerenciar a dor,

f) Reestruturação cognitiva: facilitará a apropriação de pensamentos que sinalizam afetar o gênio e entusiasmar no comportamento do portador, indicando ações mentais que o ajudará na correção de erros lógicos, 
g) Esclarece-se que esses manejos necessitam ser proporcionados por profissionais preparados afim de contribuírem na diminuição da dor proporcionando um alivio para o paciente.

h) Sua abrangência esclarece que na abordagem "Terapia Cognitivo Comportamental" ela se apresenta essencialmente no envolvimento de todos os indivíduos da família, que auxiliarão no processo de tratamento da doença, fortalecendo e, sendo imprescindível na prevenção de gerir os conflitos existenciais, destacando a necessidade do acompanhamento psicológico para que a família compreenda e contribua nesse processo e acrescenta que mesmo com a resolução das queixas destacada pelo doente, ele necessitará da participação direta ou indireta de toda a família, sendo necessário um olhar diferenciado dos profissionais em compreender a dinâmica de cada individuo, em seu meio social, cultural e econômico, em especial, nos estágios em a dor se apresenta (CORDEIRO, 2018).

Comumente isso acontece porque as terapias se apresentam como indispensável no espaço social e destaca a necessidade dos cuidados primário da família, considerando a necessidade que ela tem em ser compreendida como um grupo dinâmico, interagindo, apoiando mutuamente na solução de problemas. Assim, a família é um sistema aberto, em transformação, cuja principal atividade é a de apoiar suas partes considerando o momento histórico, a cultura e o social que estão inseridos (GOLDENBERG, 2014).

Em concordancia, Zanete (2014) e Silva (2015), esclarecem que além da terapia e da equipe multiprofissional, o portador necessita que a família necessita ser compreendida como uma organização ativa em um processo contínuo de mudanças, gerando crescimento psicossocial de ambas as partes, considerando experimentos que podem ser reforçadores no processo ou experiências punitivas que podem prejudicar os portadores proporcionando um maior ou menor sofrimento físico e psíquico em torno da doença.

\section{MÉTODO}

\section{CRITÉRIOS DE INCLUSÃO E EXCLUSÃO}

A metodologia agregada na realização deste trabalho sucedeu através da pesquisa bibliográfica em repositórios institucionais, bem como, em livros, revistas, trabalho de conclusões de curso, artigos e bibliotecas virtuais. A pesquisa trata-se exclusivamente da pesquisa bibliográfica evidenciando portadores da síndrome fibromiálgica, utilizando as palavras chaves nas bases de dados: fibromialgia, dor crônica, tratamento e intervenções psicológicas utilizando os bancos de dados BVS-PSI e SCIELO, no idioma de publicação na língua vernácula, sendo desenvolvida no período de fevereiro de 2019 a junho de 2019 tendo como critério de inclusão dos artigos:

a) Busca de trabalhos publicados no período de 2013 a 2018,

b) Artigos em língua vernácula,

c) Artigos científicos, livros, resumos publicados em teses, dissertações, monografias e biblioteca virtuais.

De um modo geral, as buscas pela pesquisa apresentaram como objetivo em contemplar fatos ocorridos na atualidade e também apresentar bases histórias da temática mais antiga como por exemplo a fibrosite e fibromialgia.

Foram adotados como critérios de exclusão da pesquisa todos os assuntos diferentes da temática principal, que não contemplam a abordagem deste trabalho. 


\section{CONSIDERAÇÕES FINAIS}

Por meio do presente trabalho constatou-se que, o tratamento da fibromialgia é particularizado, e excepcionalmente sintomático. Considerando as pesquisas evidenciadas no decorrer dessa temática, fica evidente que há uma redução do sofrimento de seus portadores, e uma evolução da funcionalidade do manejo do tratamento, especialmente ao processo psicoterapêutico juntamente com a particularidade na medida do possível da autonomia pessoal e da qualidade de vida de cada portador.

De modo geral, conclui-se que a fibromialgia é uma síndrome crônica e que necessita de acompanhamento afim de diminuir as dores sentidas no corpo durante períodos intensos. Além de apresentarem sensibilidade nas articulações, nos músculos, tendões e em outros tecidos moles acometidos pela doença estando diretamente ligada à fadiga, distúrbios do sono, dores de cabeça, depressão e ansiedade. Dessa forma, destaca-se a importância do diagnóstico correto realizado pelo médico especialista em fibromialgia, o reumatologista, sendo iniciado o tratamento medicamentoso e a psicoterapia, afim de explicar sobre a síndrome e se necessário, o encaminhamento ao psiquiatra para avaliar possíveis comorbidades.

Compreende-se que, se faz necessário um olhar diferenciado dos profissionais em compreender a dinâmica de cada portador, em seu meio social, cultural e econômico, reconhecendo as estratégias e adotando cuidados adequados a fim de amenizar os impactos da dor, interagindo e apoiando mutuamente na dinâmica do portador.

Assim, os objetivos do trabalho foram alcançados, destacando-se a importância do psicólogo junto ao tratamento da síndrome ao portador e sua família, no esclarecimento da doença, e suas complicações, através das técnicas psicoterápicas possibilitando a prevenção e promoção de sua saúde, sendo uma doença crônica, o fato de não haver uma piora é uma prevenção e estará promovendo também a saúde desse indivíduo.

A problematização da pesquisa obteve a resposta a indagação: quais os aspectos da atuação do psicólogo que auxiliam no tratamento de pacientes fibromialgico? Em resposta, conclui-se que diversas técnicas e abordagens no decorrer da pesquisa mostraram se eficazes no tratamento de pacientes com essa patologia ou outras comorbidades, especialmente, a aplicação das técnicas psicoterapêuticas que demonstram apresentar nas pacientes um maior alívio das dores. Ainda, recuperam sua autoestima, apresentam uma evolução nos quadros de ansiedade e depressão, bem como, na qualidade do sono. Especialmente, nas orientações aos familiares na sensibilização de conhecerem os aspectos da síndrome e, poderem compreender o seu portador e de quão importante é o seu apoio durante o tratamento e a manutenção.

Neste sentido, o instrumento de coleta de dados para realização desta pesquisa foi utilizado repositórios, com acesso a pesquisas recentes referente ao tema abordado é vantajoso, por se tratar de pesquisas atuais, já que os livros na maioria das vezes, estão com estudos desatualizados, concluindo também que há poucos estudos publicados com esta temática, necessitando assim, que haja continuidade das pesquisas sobre as contribuições ou manejo do psicólogo no acompanhamento de pacientes portadores de fibromialgia.

Por fim, referente aos entraves para o desenvolvimento desta pesquisa, a maior dificuldade foi por ter poucos artigos relacionados com o objetivo desde trabalho, desta forma, este trabalho não esgota as pesquisas a respeito do tema, restando ainda abordagens e lacunas a serem estudadas, sugere-se novas pesquisas. 


\section{REFERÊNCIAS}

ABREU. A.M.L.R. TCC - Limiares de dor, Níveis séricos e Variantes genéticas de serotonina em Fibromialgia: Uma Associação De Base Familiar. Canoas-RS, 2016. Recredenciamento: Portaria 1.473 de 25/5/04 - D.O.U. de 26/5/04. http://www.scielo.br/scielo. Acesso 15 de outubro 2018.

BALLONE, G.J.; ORTOLANI, . V.; PEREIRA NETO, E. Da Emoção à Lesão: Um guia da medicina psicossomática. 2. ed. São Paulo: Manole, 2007.

CÂMARA DOS DEPUTADOS. Congresso. Câmara dos Deputados. Projeto de Lei no 8807-A. Institui o Dia Nacional de Conscientização e Enfrentamento à Fibromialgia. Brasília, 25 abr. 2018. Disponível em: http://www.camara.gov.br .Acesso em: 10 set. 2018

CORDEIRO, V.N.et al. A dor crônica: experiência de pacientes em tratamento de fibromialgia. 2018. Disponível em http://tede2.unicap.br:8080/handle/tede/1025. Acesso em 08 de abril de 2019.

DICIONÁRIO AURÉLIO B.de H. F. Dicionário da língua portuguesa, 5. a edição, ISBN: 978-85-3858311-0, Ano de publicação: 2014. Acesso em 29 de setembro de 2018.

DSM V - Manual Diagnóstico e Estatístico de Transtornos Mentais - $5^{\text {a }}$ Ed. 2014, http://www.scielo.br/scielo. Acesso 15 de outubro 2018.

FACULDADE DA AMAZÔNIA. Biblioteca. Manual para elaboração de trabalhos acadêmicos; organização Cristiane Garcia Bures. - 2. ed. - Vilhena: 2018.

FERNANDES, V. Como diagnosticar e tratar a fibromialgia. Rev. bras. Med. v. 31, n. 3, p. 34-41, 2013. Acesso em http://www.scielo.br/scielo. Acesso 21 de outubro 2018.

FERREIRA, N.et al. Dor e analgesia em doente crítico. Rev Clin Hosp Prof Dr Fernando Fonseca 2014; 2(2): 17-20 http://www.teses.usp.br/teses/disponiveis/livredocencia/>. Acesso em: 15 julho 2018.

FERREIRA, A. J. O. Fibromialgia: conceito e abordagem clínica artigo de revisão. COIMBRA, PT: Faculdade de Medicina da Universidade de Coimbra, 2015. Acesso em http://www.scielo.br/scielo. Acesso 27 de outubro 2018.

GAVI, M.B.et al. O uso do mini-exame do estado mental colabora no tratamento da fibromialgia. Ciências \& Cognição, v. 23, n. 1, 2018. Disponível em file:///C:/Users/user/Downloads/1397-9527-1-PB.pdf. Acesso em 08 de abril de 2019.

GOULART R; PESSOA C; JÚNIOR IL. Aspectos psicológicos da síndrome da fibromialgia: revisão de literatura. Rev Bras Reumatol. 2016; Acesso em http://dx.doi.org/10.1016/j.rbr.2015.07.008. Acesso 18 de outubro 2018.

GOLDENBERG E. O Coração Sente o Corpo Dói: Como reconhecer e tratar a fibromialgia 7.ed. São Paulo: Atheneu, 2014. Acesso em http://www.scielo.br/scielo. Acesso 28 de outubro 2018.

LAKATOS, E. M.; MARCONI, M. de A. Fundamentos de metodologia científica. 8 ed. São Paulo: Atlas, 2015

LAVÍN MM. Fibromialgia sem mistério: um guia para pacientes, familiares e médicos. São Paulo: MG Editores, 2014. http://www.scielo.br/scielo. Acesso 15 de outubro 2018.

LIMA, M.A.G.; TRAD, L. Dor crônica terapia cognitiva comportamental. Hist. cienc. Saúde Manguinhos, Rio de Janeiro, v. 15, n. 1, agosto de 2018. Acesso em http://www.scielo.br/scielo. Acesso 18 de outubro 2018. 
MARQUES, A. P. Qualidade de vida de indivíduos com fibromialgia: poder de discriminação dos instrumentos de avaliação. 2015. 80 f. Tese (livre-docência) - Faculdade de Medicina da Universidade de São Paulo, São Paulo, 2004. Acesso em: 23 setembro 2018.

NÓBREGA, P.A. (2014) Como escutar um corpo que dói? Reflexão sobre acontecimento de corpo e transferência. Dissertação de Mestrado, Universidade Católica de Pernambuco, PE, Brasil. Acesso em http://www.scielo.br/scielo. Acesso 28 de outubro 2018.

OLIVEIRA, E.M.S. TCC - Técnicas da Terapia Cognitivo-Comportamental para o tratamento de fibromialgia. Alarcon - São Paulo, 2015. Acesso em http://www.scielo.br/scielo. Acesso 18 de outubro $\underline{2018}$.

OLIVEIRA JUNIOR, J.O.de; ALMEIDA, M.B. de. O tratamento atual da fibromialgia. BrJP, São Paulo, v. 1, n. 3, p. 255-262, jul. 2018. Disponível em <http://www.scielo.br/scielo . Acessos em 23 abr. 2019.

ORGANIZAÇÃO MUNDIAL DA SAÚDE (OMS). Classificação de transtornos mentais e de comportamento da CID 10: descrições clínicas e diretrizes diagnósticas. Fibromialgia enigma corporal. Artes Médicas, Porto Alegre, 2016. Acesso 11 outubro 2018.

ROCHA ASRM. Catastrofização da Dor e Percepção de Doença em Indivíduos com Dor Crónica. Dissertação (Mestrado em Psicologia Clínica e da Saúde). Faculdade de Ciências Humanas e Sociais da Universidade Fernando Pessoa do Porto. Porto-2013.

SBR, Sociedade Brasileira de Reumatologia- Fibromialgia: Cartilha para pacientes; São Paulo, 2018. http://www.dor.org.br/brasil. Acesso 15 outubros 2018

SILVA, V.F. Abordagem fisioterapêutico no tratamento da fibromialgia. 2018. 30 fls. Trabalho de Conclusão de Curso Fisioterapia - UNIC - Universidade de Cuiabá, Cuiabá - MT, 2018. Acesso em http://www.scielo.br/scielo. Acesso 18 de setembro 2018.

TORQUATO, A. C.et al. Comparação entre os resultados obtidos por diferentes métodos de avaliação da composição corporal em mulheres com síndrome de fibromialgia. RBONE-Revista Brasileira de Obesidade, Nutrição e Emagrecimento, v. 13, n. 77, p. 103-110, 2019. Disponível em http://www.scielo.br/scielo. Acesso em 08 de abril de 2019.

ZANETE SA. Sistema modelador descendente da dor na fibromialgia: mediadores séricos e efeito da melatonina ensaio clínico fase II, Double-Dummy, controlado. Tese. (Doutorado em Medicina Ciências Médicas). Universidade Federal do Rio Grande do Sul, 2014. Acesso em http://www.scielo.br/scielo. Acesso 11 de agosto 2018. 